\title{
Efektivitas model Outreach Counseling dalam meningkatkan kemandirian anak tunagrahita
}

\author{
Jon Efendi ${ }^{1}$, Rendy Amora $\mathbf{J}^{2}$ \\ ${ }^{12}$ Univeristas Negeri Padang
}

\begin{tabular}{l}
\hline Article Info \\
\hline Article history: \\
Received May 17th, 2020 \\
Revised Jun 21st, 2020 \\
Accepted Jul 23rd, 2020
\end{tabular}

Keyword:

Outreach Counseling

Kemandirian

Anak Tunagrahita

\begin{abstract}
This study is a test of the effectiveness of the Outreach counseling model in increasing the independence of mentally retarded children. Through Single Subject Research Design (SSRDs) using A-B-A Design. The findings show; 1) the actual condition of mentally retarded child independence is not yet fully independent, 2) the effectiveness test is that the outreach counseling model can; lowering the percentage of not being independent, increasing independence with assistance, and increasing independence for children with moderate mental retardation. The Outreach Counseling model is recommended to be carried out by the principal as the coordinator of guidance, teachers, parents, family members, and involves the closest environment to children with moderate mental retardation.
\end{abstract}

(C) 2020 The Authors. Published by Indonesian Institute for Counseling,

Education and Therapy (IICET). This is an open access article under the CC BY license (https://creativecommons.org/licenses/by/4.0/)

\author{
Corresponding Author: \\ Jon Efendi \\ Universitas Negeri Padang \\ Email: jofipasi@yahoo.com
}

\section{Pendahuluan}

Kemandirian bagi Anak Tunagrahita (ATG) merupakan sesuatu kondisi dimana mereka tidak tergantung pada bantuan orang lain. Rendahnya kemandirian anak disebabkan karena faktor kekhawatiran orang tua (over protection) (Ahman; 1998). Selain itu rendahnya kemandirian anak tunagrahita juga dapat disebabkan oleh beberapa faktor yang melatarbelakangi (Henry, L. \& MacLean; 2002). Fenomena yang terjadi menunjukkan bahwa sebagian besar ATG menunjukkan ketidakmatangan dalam hal kemandirian, terutama pada kemampuan mengurus diri sendiri.

Keterampilan mengurus diri sendiri merupakan kemampuan yang sangat penting bagi ATG. Kemampuan itu meliputi: 1) keterampilan hidup sehari-hari, seperti berpakaian, aktivitas di kamar mandi, dan makan sendiri (Nichcy; 2011). Pendapat Wehman\& Laughlin; 1981 bahwa; 1) orang tua lebih sering mengambil alih pekerjaan ATG, 2) ATG tidak mendapatkan bimbingan yang memadai, 3) kerjasama guru dan orang tua perlu ditingkatkan, 4) perlu alternatif layanan bimbingan dangan melibatkan lingkungan terdekat anak, 5) aksesibilitas agar ATG lebih mudah beraktivitas.

Hubungan timbal balik dengan anggota keluarga dan mengembangkan hubungan dengan anggota masyarakat juga membantu membangun guru sebagai bagian dari hubungan timbal balik, yang berarti mereka ada di sana untuk belajar dan berkontribusi kepada masyarakat (Dettmer Peggy, 2005; Moll, 1992). Upaya penjangkauan untuk membangun konseling dalam hubungan pada tingkat pribadi terbukti membantu dalam memasukkan dana pengetahuan siswa ke dalam kurikulum dan dalam membantu pendidik memandang siswa, orang tua, dan komunitas mereka sebagai sumber pengetahuan (Okoji; 2008). Upaya penjangkauan pada anak tunagahita dapat dilakukan dengan outrech counseling, yaitu melakukan konseling terhadap ATG dengan bantuan orang-orang berada di lingkungan terdekat.

Outreach counseling merupakan suatu program pendekatan koseling untuk memaksimalkan layanan konseling sebagai alternatif bila proses koseling secara umumnya sulit dilakukan oleh konselor. Outreach 
untuk memperpanjang jangkauan konseling seperti kutipan Deborah J. Taub, (2011) yang mengatakan program penjangkauan adalah salah satu cara untuk memperluas jangkauan pusat konseling dan sumber daya disekolah. Outrech counseling memberikan kesempatan untuk fokus pada pendidikan dan pencegahan, menjangkau populasi siswa yang kurang dapat diakses, dan melayani kelompok siswa daripada individu."(Archer \& Cooper, 1998; Marks \& McLaughlin, 2005). Materi bimbingan yang memandirikan dapat berupa kecakapan hidup sehari-hari (daily living activities)."(Depdiknas; 2008).

Tugas guru sebagai konselor di SLB adalah menangani masalah siswa. Pelayanan guru sebagai pembimbing siswa tunagrahita akan mengalami berbagai kendala sesuai dengan kondisi dan karakteristik siswa (Corvelay; 2010). Sedangkan siswa tunagrahita mengalami kesulitan dengan kondisi yang menyertainya, sehingga mereka sulit untuk membuat keputusan yang berdampak pada kehidupannya. Model Outrech counseling akan memberikan intervensi berupa jangkauan konseling kepada anak tunagrahita melalui bantuan orang lain yang sebagian besar berasal dari keluarga atau lingkungan (Alimin; 2006).

Penjangkauan konselor dikatakan "berhasil" apabila dapat mengidentifikasi dan mendemonstrasikan strategi konseling yang sesuai untuk populasi yang beragam dan mampu menyesuaikan gaya konseling untuk secara efektif menanggapi kebutuhan siswa mereka (Okoji; 2008). Intervensi untuk siswa tunagrahita memiliki jangka panjang dan akan berdampak pada kemandirian atau penentuan nasib sendiri .Sebagian besar siswa tunagrahita kurang mampu menjalankan aktivitasnya secara mandiri tanpa adanya bantuan lingkungan (Westling, D. L. \& Murden; 2008). Ketergantungan dalam waktu lama akan berdampak pada penentuan nasib sendiri atau ketidakmandirian anak.

Bimbingan dan Konseling merupakan upaya guru untuk memfasilitasi siswa tunagrahita, agar anak bisa berkembang secara optimal, mampu mengarahkan dirinya secara mandiri sehingga terlepas dari permasalahan yang membebani dirinya (Depdiknas; 2007). Penerapan bimbingan bagi siswa tunagrahita di SLB belum ditangani sepenuhnya oleh guru. Untuk itu perlu dilakukan penelitian yang mendalam untuk mengetahui seberapa besar efektivitas model outrech counseling terhadap kemandirian anak tunagrahita di Sekolah Luar Biasa.

\section{Metode}

Penelitian ini Single Subjeck Research Disign (SSRDs) dengan menggunak A-B-A desain. Dimana pendekatan kuantitatif dan kualitatif digunakan secara terpadu dan saling mendukung (Thomas E. S, Margo A. M, at all; 2007). Seperti yang disarankan oleh Linda H. F, T. Steuart W, at all. (2002), bahwa untuk mempelajari individu dan efektivitas intervensi konselor dapat dicapai dengan single subject research dan juga lebih meningkatkan kepekaan peneliti melaluli penelitian. Studi kasus awal tidak dikontrol ketat dan metode ini bergantung pada Kelompok temuan yang bersifat individual. Lebih lanjut ditegaskan oleh (Bruce et al, 2005.; McDougall \& Smith, 2003; Sharpley, 2001) bahwa, Single Subject Research Design (SSRDs) dipromosikan untuk penerapan praktik agar dengan mudah menggabungkan treatmen terhadap klien.

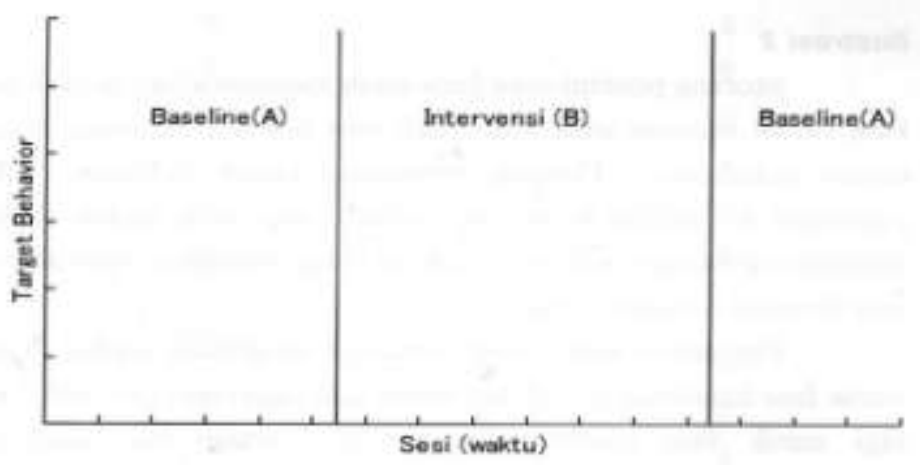

Gambar 1. A-B-A Desain

A-B-A disain seperti gambar di atas menggambarkan pelaksanaan kondisi baseline kemandirian ATG (Orhan Cakiroglu; 2012). Selanjutnya akan dilaksanakan fase intervensi yang mampu menggambarkan terjadinya peningkatan kemandirian ATG. Setelah intervensi maka akan dilakukan lagi pemotretan kondisi 
baseline ke dua yang bertujuan untuk memberikan perbandingan antara fase baseline (A1) dan treatment (B) dengan memperhatikan baseline ke dua (A2) (Linda H; 2010).

Penelitian dilakukan pada lima Sekolah Luar Biasa dikota padang, dengan subjek penelitain anak tunagrahita kelas rendah yang dipilih secara random. Ada tiga target behavior pada penelitian yakni; 1) tidak mandiri (TM), 2) mandiri dengan bantuan (MDB), 3) mandiri (M) (McMillan \& Schumacher; 2008). Intervensi melalui model outrech konseling merupakan hasil dari target behavior, dengan kata lain jika target yang ditetapkan tercapai maka dapat dikatakan bahwa model outrech conseling yang dilakukan efektif dalam meningkatkan kemandirian pada anak tunagrahita. Pada penelitian ini peneliti berkolaborasi dengan beberapa pihak-pihak yang memiliki keterkaitan dengan anak tunagrahita.Yang dimaksud kolaborasi dalam penelitian ini adalah kolaborasi dalam penelitian tindakan terhadap kegiatan yang dipelajari. Peneliti berada di lapangan sejak awal penelitian dan bersama guru melakukan penelitian dan menganalisis serta menyusun program hipotetik yang sesuai dengan karakteristik anak tunagrahita ringan. Untuk lebih jelasnya dapat dilihat pada gambar bagan model konseptual dibawah:

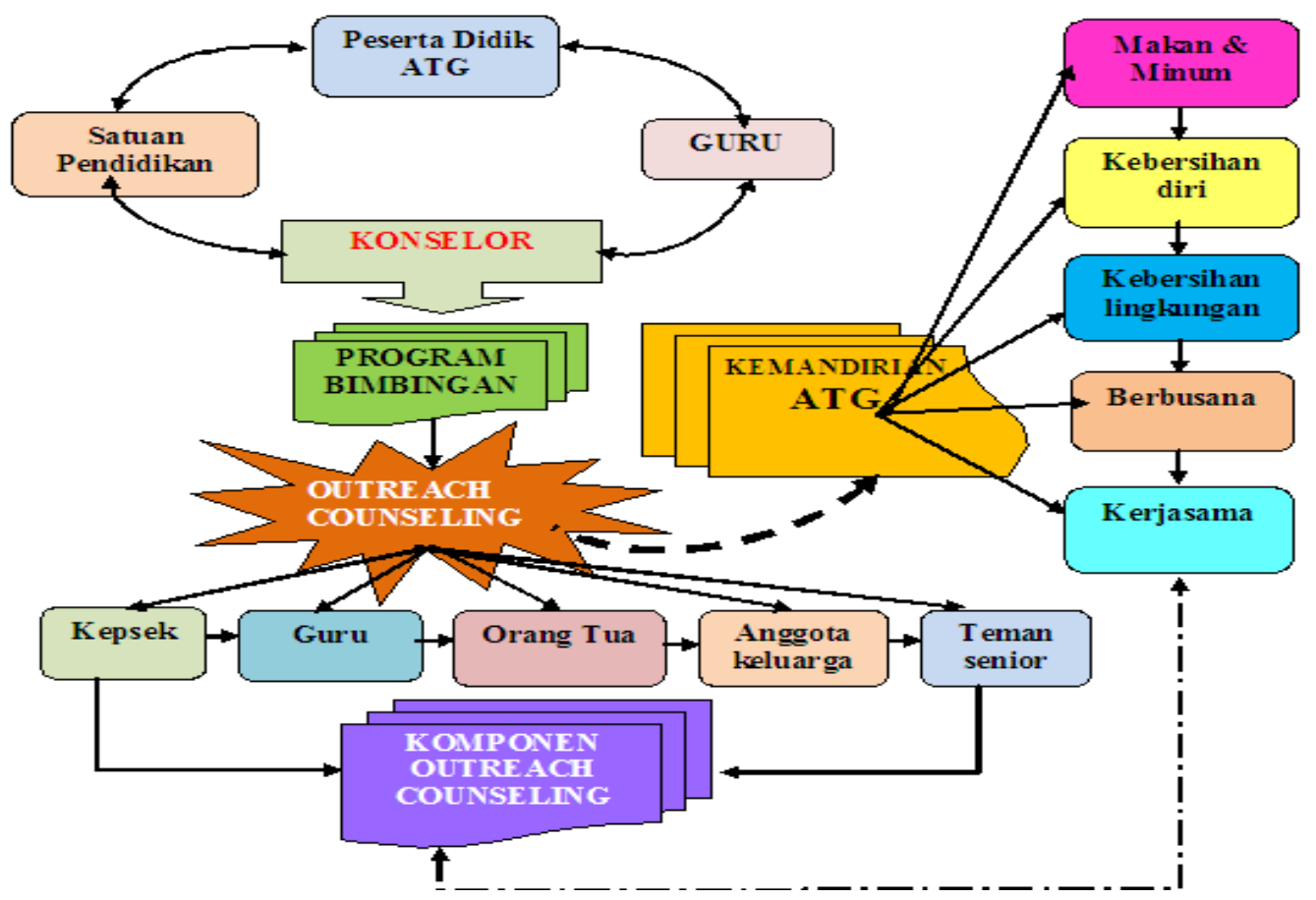

Gambar 2. Konseptual Model Outreach Counseling

\section{Hasil dan Pembahasan}

Gambaran data baseline kemandirian ATGS dalam penelitian ini yakni; 1) SLBN 2 Padang, 2) SLB YPPLB Padang, 3) SLB Wacana Asih Padang, 4) SLB Kasih Ummi Padang, 5) SLB YPAC Padang. Data baseline ditampilkan dalam bentuk tabel berupa skor persentase (\%) yang selanjutnya di rekapitulasikan menurut para pengamat. Data tersebut digambarkan seperti tabel 1.

Selanjutnya dilakukan evaluasi terhadap Data baseline yang didapatkan dari para pengamat diatas. Evaluasi terhadap model bertujuan untuk mengetahui seberapa besar ketercapaian model outreach counseling. Untuk memperoleh umpan balik terhadap keefektifan model outreach counseling akan disesuaikan dengan disain eksperiment A-B-A SSRDs. Pemilihan Design A-B-A diharapkan akan mampu digunakan sebagai acuan dalam melaksanakan eksperiment dalam penelitian, Linda H. F, T. Steuart W, at all. (2002). Evaluasi program dilakukan dengan cara berkolaborasi antara peneliti dan kepala sekolah sebagai koordinator guru pembimbing atau konselor sekolah. Selain dengan kepala sekolah juga dilakukan diskusi dengan melibatkan; guru kelas, orang tua, anggota keluarga, dan juga teman senior .Dari informasi ini dapat diketahui sejauh mana keberhasilan layanan model outreach counseling untuk meningkatkan kemandirian ATG. Informasi ini dapat ditetapkan sebagai tindak lanjut (follow up) untuk memperbaiki dan mengembangkan model selanjutnya. Pembuktian terhadap keberhasilan model di lapangan, dilakukan dengan cara mengevaluasi model outreach counseling yang telah diintervensikan melalui sesi dan durasi 
pertemuan, untuk mengembangkan kemandirian ATG, mulai dari perencanaan, evaluasi proses dan hasil bimbingan kemandirian.

Tabel 1. Data Baseline

\begin{tabular}{|c|c|c|c|c|c|c|c|c|c|c|c|c|c|c|c|}
\hline \multirow[t]{3}{*}{ Subyek } & \multicolumn{15}{|c|}{ \% Skor Responden } \\
\hline & \multicolumn{3}{|c|}{ Kepsek } & \multicolumn{3}{|c|}{ Guru } & \multicolumn{3}{|c|}{ Ortu } & \multicolumn{3}{|c|}{ Keluarga } & \multicolumn{3}{|c|}{ Teman Senior } \\
\hline & 1 & 2 & 3 & 1 & 2 & 3 & 1 & 2 & 3 & 1 & 2 & 3 & 1 & 2 & 3 \\
\hline $\begin{array}{l}\text { SF } \\
\text { (SLBN2) }\end{array}$ & 30 & 66.5 & 3.5 & 31 & 65 & 6 & 36.5 & 47.5 & 16 & 34 & 44 & 22 & 42.5 & 37 & 20.5 \\
\hline $\begin{array}{l}\text { AN } \\
\text { (YPPLB) }\end{array}$ & 6.5 & 24.5 & 69 & 6 & 27 & 67 & 5 & 28.5 & 66 & 4.5 & 28 & 60 & 20 & 48 & 32 \\
\hline $\begin{array}{l}\text { ZW } \\
\text { (SLB WA) }\end{array}$ & 5 & 52 & 43 & 4.5 & 21.5 & 74 & 6 & 18 & 76 & 9.5 & 23 & 67 & 21 & 47 & 32 \\
\hline $\begin{array}{l}\text { M. Refat } \\
\text { (SLB KU) }\end{array}$ & 78 & 12.5 & 9.5 & 71 & 24 & 5.5 & 22 & 49.5 & 28.5 & 72.5 & 25 & 2.5 & 61.5 & 20 & 18.5 \\
\hline $\begin{array}{l}\text { Ari P (SLB } \\
\text { YPAC) }\end{array}$ & 4.5 & 27.5 & 68 & 9 & 43.5 & 47.5 & 5 & 51 & 44 & 5 & 53.5 & 41.5 & 18 & 41.5 & 40.5 \\
\hline$\sum$ Total & 24.8 & 36.6 & 38.6 & 24.2 & 36.2 & 40 & 14.9 & 38,9 & 46.1 & 25.5 & 32.3 & 38.6 & 32.6 & 38.7 & 28.7 \\
\hline
\end{tabular}

Keterangan: $\quad 1=$ Tidak mandiri

$2=$ Mandiri dengan bantuan

$3=$ Mandiri

Berikut adalah hasil evaluasi dari outrech counseling Berdasarkan pengolahan data pada salah seorang ATG melalui persentase yang digambarkan dalam bentuk grafik seperti di bawah ini:

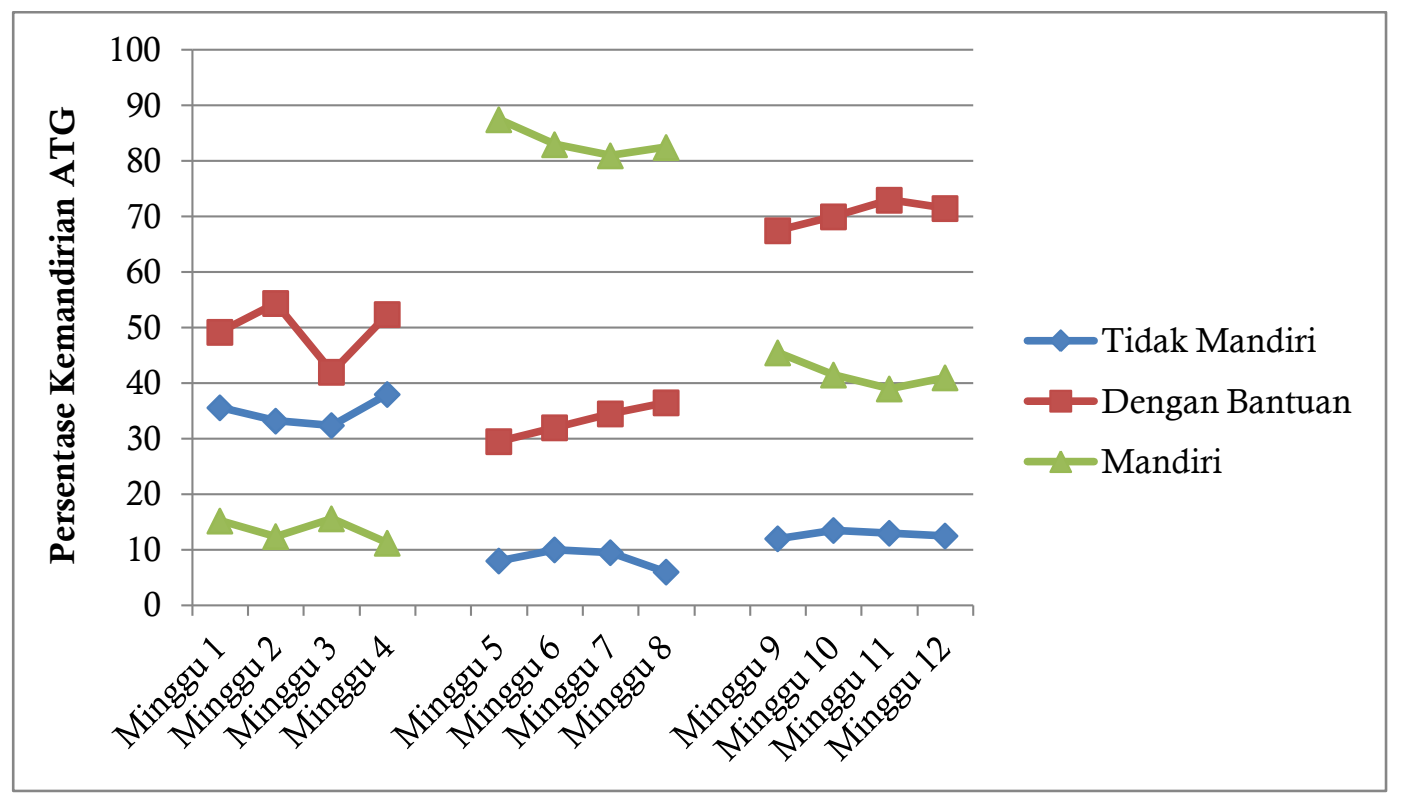

Gambar 3. grafik hasil evaluasi model outrech conseling

Berdasarkan grafik di atas secara keseluruhan mengisaratkan bahwa kemandirian anak menunjukkan peningkatan. Jika di amati setelah treatment melalui bimbingan outreach counseling dapat menurunkan tingkat persetase tidak mandiri anak. Hal ini digambarkan melalui grafik yang menunjukkan selalu terjadi penurunan angka peresentase tidak mandiri bagi anak. Kemandirian dengan bantuan semakin meningkat dan Kegiatan yang mampu dilakukan secara mandiri menunjukkan peningkatan yang cukup berarti. Dengan adanya peningkatan kemandirian pada ATG setelah dilakukan treatment melalui model outrech konseling, dapat dikatakan bahwa outrech konseling efektif dalam meningkatkan kemandirian pada ATG.

Hasil penelitian menunjukkan kemandirian Anak Tuna Grahita (ATG) dalam kegiatan sehari-hari di sekolah masih mengharapkan bantuan ataupun mendapat intervensi dari lingkungan terdekat. Lingkungan terdekat seperti; orang tua, saudara, kakek/nenek, atau orang lain di lingkungan rumah. Akibatnya ATG menunggu belas kasihan orang lain dengan menunggu diam ditempatnya tanpa mampu berbuat lebih 
banyak untuk kemandiriannya (Thomas A. C, at all; 2008). Hasil penelitian oleh Lazarus et al., (2011), menyatakan faktor- faktor yang dapat mempengaruhi kemampuan kemandirian pada anak usia sekolah adalah: 1) faktor demografi (usia, jenis kelamin, status sosial ekonomi); 2) faktor sosial kultural (budaya dan dukungan sosial); 3) faktor psikososial (konsep diri, rasa percaya diri, dan tipe kepribadian); 4) faktor fisik (kondisi kesehatan, kemampuan beraktivitas, disabilitas yang dialami). Anak yang berusia lebih tua memiliki kemampuan perawatan diri lebih baik dari anak dengan usia yang lebih muda (Wong et al., 2002).

David McConnell (2002) mengungkap kemampuan perawatan diripada anak usia sekolah dengan sindrom nefrotik mendapatkan bahwa pada anak berusia 6-8 tahun mampu melakukan perawatan mandiri sebesar 83\%, pada anak usia 9-10 tahun sebesar 95\%, dan semua anak usia 11-12 tahun yang menjadi respoden dapat melakukan perawatan mandiri. Guru dituntut untuk mengembangkan layanan bimbingan, yang lebih mampu memberdayakan lingkungan ATG agar mereka dapat dijangkau dalam proses bimbingan yang lebih luas. Melalui counseling community diharapkan dapat dijangkau sesuai dengan kultur budaya masyarakat dimana bimbingan dilakukan. Dalam hal ini termasuk anak terbelakang mental ataupun anak yang mengalami difabel lainnya.

Kegiatan bimbingan yang mampu mengembangkan dan memperluas jangkauan di sebut dengan istilah Outreachcounseling. Menurut Buckley (2006) bahwa; guru harus selalu berinovasi, berusaha mencari alternatif program sekolah. Outreach counseling berlaku untuk penjangkauan masyarakat dan mengacu pada upaya peningkatkan layanan, dan telah digunakan sejak tahun 1974. Istilah"outreach" muncul pertengahan tahun 1990. Outreach counseling merupakan suatu model bimbingan konseling untuk memaksimalkan layanan sebagai alternatif bila proses konseling secara umumnya sulit dilakukan oleh konselor. Melalui Outreach lebih mengarahkan pada sikap konselor untuk mengambil sikap aktif dan tidak hanya membatasi program kerjanya bagi klien yang membutuhkan bantuan dalam mengatasi masalahnya. Berkenaan dengan keterbatasan dalam kecerdasan yang berdampak pada rendahnya kemandirian ATG, oleh karena itu model outreach counseling dalam memnantu meningkatkan kemandirian dirasakan sangat diperlukan. Caranya dengan melibatkan orang-orang di lingkungan terdekat, agar dapat berperan serta dalam proses konseling untuk meningkatkan kemandirian ATG.

\section{Kesimpulan}

Outreach Counseling mampu memberikan Pendekatan Konseling Untuk Memaksimalkan Layanan Konseling Sebagai Alternatif Jika Proses Konseling Secara Umum Sulit Bagi Konselor. Bimbingan Outreach Perlu Menyentuh Berbagai Upaya Dalam Membantu ATG Untuk Berkembang Secara Optimal, Dan Mampu Mengatasi Masalah Kemandirian, Sehingga Konselor Tidak Perlu Melibatkan Diri Secara Langsung. ATG banyak memerlukan campur tangan dan mendapat bantuan orang lain. Lebih dari separuh kegiatan harian bagi ATG dilakukan dengan mendapat bantuan orang lain, dan hanya sebagiankecil kegiatan kemandirian dapat dilakukan secara mandiri. Berdasarkan data penelitian Perbedaan antar kondisi baseline (A1), kondisi intervensi (B) dan kondisi baseline (A2) disimpulkan bahwa terjadi perubahan yang positif dalam peningkatan kemandirian ATG. Bedasarkan analisis, didapatkan Kesimpulan efektivitas kemandirian ATGS dinyatakan terjadi peningkatan yang lebih baik. Dengan demikian model outreach counseling efektif dalam meningkatkan kemandirian ATG di Kota Padang.

\section{Referensi}

Ahman, (1998). Bimbingan Perkembangan: Model bimbingan dan Konseling di Sekolah dasar. Disertasi. PPS IKIP Bandung: Tidak diterbitkan.

Amin, M. (1995).OrthopedagogikAnakTunagarahita. Jakarta: Depdikbud dikti, Proyek pendidikan tenaga Guru Archer \& Cooper.(1998). Pp 131 -132.Journal Of College Counseling/Spring 1999/Vol.2

Bosco. (2012). Diakses Darihttp://Www.Bosco.Org.2012.

Bruce A. C, at all. (2005). A Methodology for the Quantitative Synthesis of Intra-Subject Design Research. J Spec Educ 2005 19: 387. http://sed.sagepub.com/content/19/4/387

Buckley, S., Bird, G. \& Sacks, B. (2006) Evidence Based That we can change the profile form a study of inclusive education, Down Syndrome: Rest Pract. 9. 51-53

Clinton, Dkk. (2011). Tersedia: Become Outreach Counselor. Diakses dari http://Www.Ehow.Com/How_2065309_Become-Outreach-Counselor.Html\#Ixzz1Xt4ebqel 17

Februari 2011

Crego, (1990). Journal Of College Counseling/Spring 1999/Vol.2 
Corvelay.(2010). Becomespecial Education Counselor. Diakses Dari http://Www.Ehow.Com/How_4897826_Become-Special-EducationCounselor.Html\#Ixzz1Xt6dqdbm

David McConnell and Gwynnyth Llewellyn. (2002) Stereotypes, parents with intellectual disability and child protection, Faculty of Health Sciences, University of Sydney Journal of Social Welfare and Family Law ISSN 0141-8033 print/ISSN 1469-9621 online (C) 2002 Taylor \& Francis Ltd.

Deborah J. Taub, (2011). Developing Skills in Providing Outreach Programs: Construction and Use of the POSE (Performance of Outreach Skills Evaluation) Rubric. sagepub.com/journalsPermissions.nav DOI: $10.1177 / 2150137811401019$ http://core.sagepub.com

Depdiknas (2007). Petunjuk Pelaksanaan Kurikulum SLB-C, Pedoman bimbingan dan Penyuluhan, Jakarta.

Dettmer Peggy, at all. (2005) Consultation, Collaboration, And Teamwork For Students With Special Needs, 5/E. Allyn \& Bacon/Longman Www.Ablongman.Com

Drum, D.J. Howard, Fifler. E. (1977).Outreach In Conseling, Diaksesdarihttp://Www.Sagepublications.Com

Evette, J. L., Susan, J. C., Dkk. (1999).Implementation Of Outreach Telephone Counseling To Promote Mammography Participation. Health Education \& Behavior, Vol. 26 (5): 689-702 (October 1999) (C) 1999 By Sophe. Diaksesdari Http://Heb.Sagepub.Com/Content/26/5/689

Ford L. C Dkk. (2007).Key Components Of A Theory-Guided Hiv Prevention Outreach Model: Pre-Outreach Preparation, Community Assessment, And A Network Of Key Informants. Aids Education And Prevention, 19(2), 173-116, 2007 C 2007 The Guilford Press.

Galvin, W. F, (2012).Brain Injury And Statewide Specialized Community Services, Massachusetts Rehabilitation Commission27 Wormwood Street Suite 600 Boston, Ma 02210-1616617-204-3852, 800-223-2559, x2 (TollFree)Diaksesdariwww.Mass.Gov/Mrc/Ship

Geldard, K. And Geldard, D. (2011). Konseling Anak-Anak Panduan Praktis, Edisi Ketiga, Pustaka Pelajar.

Henry, L. \& MacLean, M. (2002) Working memory performance in children with and without intellectual disabilities. American Journal on Mental Retardation, 107(6), 421-423.

Lazarus, Kelechi U. (Ph. D), (2011). The Role Of Guidance Counsellors In The Career Development Of Adolescents And Young Adults With Special Needs, British Journal of Arts and Social Sciences ISSN: 2046-9578, Vol.2 No.1 (2011) Tersedia http://www.bjournal.co.uk/BJASS.aspx

Lewis, A.J., Lewis, M. D., Dkk. (2011). Community Counseling.A Multicultural-Social Justice Perspective.Fourth Edition. Brooks Cole.

Linda H. F, T. Steuart W, at all. (2002). Single-subject research design for school counselors: Becoming an applied researcher. Professional School Counseling, 6(2), 146-154. American School Counselor Association: http://www.schoolcounselor.org/

Linda H. Foster, (2010). A Best Kept Secret: Single-Subject Research Design in Counseling sagepub.com/journalsPermissions.nav DOI: 10.1177/2150137810387130 http://core.sagepub.com

Marks, L. I., \& McLaughlin, R. H. (2005). Outreach by college counselors: Increasing student attendance at presentations. Journal of College Counseling, 8, 86-96Odom L.Samuel, Brantlinger E. (2005).Dkk. Research In Special Education:Scientific Methods And Evidence-Based Practices. Vol. 71, No. 2, Pp. 137-148. (C)2005 Council For Exceptional Children

McMillan, H. J \& Schumacher, S. (2008). Research in Education, A Conceptual Introduction. Longman. New York \& London. Translated by; Asep Saepul Hayat.

Nichcy (2011). Intellectual Disabilities, Disability Fact Sheet \#8 Tersedia di; http://nichcy.org January 2011

Okoji, O. L.K, (2008). Bridging The Gap Between Home And School Cultures For At-Risk Secondary Students: A Sociocultural Approach To Outreach Counseling In Hawai'i, Disertation. Doctor Of Philosophy.Diaksesdari Proquest Llc 789 E. Eisenhower Parkway Po Box 1346 Ann Arbor, M1 48106-1346

Orhan Cakiroglu. (2012). Single subject research: Applications To Special Education. British Journal of Special Education (C) 2012 NASEN. Published by Blackwell Publishing Ltd, 9600 Garsington Road, Oxford OX4 2DQ, UK and 350 Main Street, Malden, MA 02148, USA. DOI: 10.1111/j.14678578.2012.00530.x

Sunardi, (2005).Pedomanpelaksanaan Bp Di SLB. Bandung: PLB FIP UPI

Thomas A. C, at all, (2008). The Family Outreach Model: Tools for Engaging and Working With Families in Distress. Journal of Family Social Work. Vol. 11(2) Tersedia di http://jfsw.haworthpress.com

Thomas E. S, Margo A. M, at all, (2007) The Quantitative Synthesis of Single-Subject Research: Methodology and Validation. Remedial and Special Education 2007 8: 24 The online version of this article can be found at: http://rse.sagepub.com/content/8/2/24

Us Fed News Service, (2007).Including Us State News. Washington, D.C. 26 May 2007.

Wehman, P \& Laughlin P J, (1981). Program Development In Special Education, McGraw-Hill Book Company. 
Westling, D. L. and Murden, L. (2008) Self-Help Skills Training: A Review of Operant Studies. http://sed.sagepub.com/content/12/3/253. The online version of this article can be found at: DOI: 10.1177/002246697801200304. J Spec Educ 12: 253. January 30, 2013.

Wong, D. L et al. (2009). Keperawatan pediatrik. Volume 1. Edisi 6. Jakarta: EGC Penerbit Buku Kedokteran. 